\title{
Enhancing Public Participation, Interaction, and Innovation in Government Minitrack Introduction
}

\author{
John Carlo Bertot \\ College of Information \\ Studies, \\ University of Maryland \\ jbertot@umd.edu
}

\author{
Mitch Cochran \\ California University of \\ Management and Science \\ Mcochran.it@,gmail.com
}

\author{
Scott Roberson \\ Information and Computer \\ Sciences Dept. \\ University of Hawaii at \\ Manoa \\ scottpr@hawaii.edu
}

Open government is an approach which purposefully emphasizes and re-invigorates the basic principle of responsive, engaged, and innovative government. Through Information and Communication Technologies (ICTs), committed administrative leadership, international initiatives such as the Open Government Partnership, countries around the world have now entered an era of unprecedented transparency of government operations and decision-making intended to lead to a more responsive, accountable, collaborative, participatory, innovative, and trustworthy government.

The Enhancing Public Participation, Interaction, and Innovation in Government minitrack focuses on research and practice that that explores citizen participation, co-creation, and innovation in governmental procedures and practices facilitated through digital governmentenabled services, resources, and technologies. There are three papers in this year's minitrack.

In her paper, The Cross-National Adoption of Policy Innovation: Peer-to-Patent, Helen Liu examines network factors in the cross-national diffusion of the Peer-to-Patent crowdsourcing innovation in the public sector. The paper explores how policymakers establish social communications networks, build communities of practice, and share information designed to generate policy transfer abilities.

Jordana George and Dorothy Leidner discuss digital activism in their paper Digital Activism:

A Hierarchy of Political Commitment. In particular, they explore and build theory on the use and impact of digital activism by extending Milbrath's hierarchy of political participation to reflect digital activism as a means to enact political change through the use of digital technologies by individuals, groups, or organizations.

In Can Digital Technologies Create a Stronger Model for Democratic Participation? The Case of \#Crowdlaw, Helen Langlamet studies the Crowdlaw online crowdsourcing tool. The paper explores notions of democracy, how Crowdlaw reflects principles of democracy, and the extent to which Crowdlaw promotes, enhances, and/or enables democratic participation and engagement. 